\title{
Don Camilo, el profesor mallorquín
}

\author{
Don Camilo, o professor maiorquino \\ Don Camilo, the Mallorcan teacher \\ Ruben Daniel Méndez Castiglioni* \\ Universidade Federal do Rio Grande do Sul - Rio Grande do Sul - Porto Alegre - Brasil
}

$\odot$

\begin{abstract}
Resumen: Este trabajo pretende recordar algunas de las actividades del escritor Camilo José Cela en la isla de Mallorca, España, donde vivió durante muchos años y dejó un legado considerable, bien como editor de la revista Papeles de Son Armadans, bien como escritor, como referente cultural y, principalmente, como profesor. De más está hacer referencia a la genialidad de su obra, a todos los premios que ganó y al reconocimiento que obtuvo. Por eso estas líneas, en las que se busca vislumbrar un poco de la dimensión humana del autor por medio de relatos de quien con él estuvo en esos años isleños como alumno, como colega de Universidad, como amigo.
\end{abstract}

Palabras clave: Camilo José Cela; Profesor; Referente cultural

Resumo: Este artigo pretende recordar algumas das atividades do escritor Camilo José Cela na ilha de Mallorca, Espanha, onde viveu durante muitos anos e onde deixou um legado considerável, seja como editor da revista Papeles de Son Armadans, seja como escritor, como referente cultural e, principalmente, como professor. Desnecessário será fazer referência à genialidade de sua obra, a todos os prêmios que ganhou e ao reconhecimento obtido. Por isso, nestas linhas, o que se busca é vislumbrar um pouco da dimensão humana do autor, por meio de relatos de quem com ele conviveu nesses anos maiorquinos, como aluno, como colega de Universidade, como amigo.

Palavras-chave: Camilo José Cela; Professor; Referente cultural

\begin{abstract}
This study intents to recollect some of the activities of the writer Camilo Jose Cela in the island of Mallorca, Spain, where he lived for many years and left a considerable legacy, also as an editor of the magazine Papeles de Son Armadans, as a writer, as a cultural reference and mainly as a professor. Additionally, it's referring to the geniality of his work, all the awards he has won and the recognition he received. These lines seek to catch a glimpse of the human dimension of the author through accounts of whom was with him during those years as a student, as University colleague, and as a friend.
\end{abstract}

Keywords: Camilo José Cela; Professor; Cultural reference

Cuando llegué a Palma de Mallorca, en 1997, para realizar estudios de doctorado, todavía sonaban los ecos de la estancia del gran escritor Camilo José Cela. Vecino de Joan Miró, fue una de las figuras ilustres que allí vivieron por algunos años, desde Chopin a Jorge Luis Borges, de Rubén Darío a Robert Graves. Su presencia ha marcado tanto, y los lazos fueron tan estrechos, que hoy en día su hijo, Camilo José Cela Conde, piensa establecer

\footnotetext{
* Professor pesquisador do CNPq.
}

en Palma una sede de la fundación que lleva el nombre del escritor.

El director de tesis que me tocó en suerte no podía haber sido mejor: el profesor Perfecto Cuadrado. Perfecto había sido su colega y discípulo y, me atrevería a decir, su amigo. Mi curiosidad acerca del Nobel siempre fue mucha, y en ese momento tenía la oportunidad de saber con detalles cosas que ciertamente no estaban en los textos de los investigadores de su obra, o por ser muy personales, o por no poder o no merecer ser publicadas. $\mathrm{Y}$ algo creo haber conseguido. 
No seré yo quien traiga novedades, pero sí me gustaría compartir un poco de lo que fue divulgado por Perfecto y por María, su esposa, también profesora, también mi amiga, y en la ocasión alumna de uno de los cursos de doctorado de Don Camilo. La intención es que no se pierdan algunos detalles poco conocidos y que se renueven en la lectura, mostrando esa otra dimensión de Don Camilo. Y a eso vamos, con la modestísima intención de ser simplemente anecdóticos, y lo que es peor, con retazos ajenos de memoria personal. Pero retazos de gran valor, pues provienen de reconocidos docentes tanto nacional como internacionalmente. El uno, ganador del importante premio Luso-Espanhol de Arte e Cultura de 2008, otorgado por el gobierno portugués. La otra, distinguida recientemente con el título de Doctor Honoris Causa por la Universidad Suceava de Rumania. Antes, algo sobre Don Camilo en la isla previamente a su nombramiento como profesor y sobre la revista Papeles de Son Armadans, por él dirigida.

\section{Algo de la relación de Camilo José Cela con Palma de Mallorca}

El escritor consideraba a la isla de Mallorca como un lugar para vivir y para trabajar en paz. En el libro Camilo José Cela: Perfiles de un escritor, Adolfo Sotelo Vázquez observa que la primera relación del autor con la isla tiene como puente a Miguel Vilallonga, quien decía que el escritor le "profesaba una antipatía intuitiva", aunque le consideraba el mejor novelista del presente y del pasado, mejor que Pío Baroja, quien apenas sería su imitador (SOTELO, s/f, p. 192). Y en Baleares (edición de 21 de abril de 1944), con el título "Carta abierta a Don Camilo José Cela. En algún café. Madrid” y “para su bien", Villalonga le reprocha que frecuente esos cafés de chismografía literaria y le pide que se dedique seriamente a la literatura. Sotelo entiende que sería ese "el pórtico de la decisión" que Cela toma de instalarse en la isla. Y continúa el investigador: "hastiado de la vida literaria madrileña y con los deberes por hacer de La Catira, Cela llegó acompañado de Charo, su primera mujer, a Mallorca" (SOTELO, s/f, p. 194). El tiempo en que el autor vivió en Mallorca le marcó profundamente:

- En Mallorca he vivido y he trabajado a gusto: en Palma empecé y en Puerto Pollensa puse punto final a mi novela La catira, en la que recojo las innúmeras sugerencias de mi viaje del año pasado por tierras venezolanas; en Mallorca hice buenos y numerosos amigos...

- ¿Cuántos?

- ¡Cualquiera se atreve a enumerar! ¡Muchos! ¡Muchísimos! Quizás salvo La Coruña donde nací, y Madrid donde vivo desde niño, sea Mallorca el rincón de España donde tengo más amigos. Creo que el dato no deja de tener una pequeña importancia.

- ¿Te vas contento de la isla?

- Sí, sin duda alguna, muy contento. Mallorca ha sido para mí un descubrimiento: a pesar de la propaganda inhábil que suele hacer el turismo (En SOTELO, s/f, p. 194).

Don Camilo, que había sido definitivamente conquistado por la isla, decidió, en poco tiempo, volver: "se iniciaba así la vida mallorquina -vida larga, densa y fundamental para la cultura española del tercer cuarto del siglo XX- de Camilo José Cela en Mallorca" (SOTELO, s/f, p. 196). Los beneficios económicos de la publicación de La catira le permitieron emprender distintos proyectos. Se mudó a la calle Bosque número 1, que perteneció al antiguo barrio de Son Armadans y, en 1955, tuvo la idea de hacer una publicación dirigida al mundo literario. Comenzó a comunicarse epistolarmente con la intelectualidad española residente y con aquellos que estaban exiliados. Para el primer número pudo reunir nombres como Gregorio Marañon, Alonso Zamora Vicente, José Maria Castellet, José Maria Moreno Galván, Dámaso Alonso, Carles Riba, Rafael Sánchez Ferlosio y Ricardo Gullón.

\section{Papeles de Son Armadans}

El 28 de enero de 1956 Baleares anunciaba que el escritor había decidido no abandonarles en mucho tiempo, pues se había instalado en Son Armadans y trabajaba intensamente en una revista que se llamaría Papeles de Son Armadans. Leyendo el primer número encontramos una descripción del paisaje que así describe el autor y director de la revista a modo de "inevitable" introducción:

Desde su terraza el director de PAPELES DE SON ARMADANS puede ver, irguiéndose sobre su bosque de pinos, la silueta airosa y bien medida del manso castillo de Bellver, "el guerrero que jamás guerreó", en cuyos muros pinta sus más claros sienas el sol de la mañana. Los pinos de Bellver, verdes, albiverdes, verdinegros y azules, ignoran -benditos sean los pinos de Bellver- el acre olor de la pólvora, aunque conozcan -¡detente Satanás! el amargo y azufrado aroma que envolvieron al castellano Malo y a su consejera áulica-. Na Joana, sa "Bruixa", demoníacos y malévolos espíritus a quienes ahuyentó la espada virtuosa del Caballero de las Tres Cruces Negras, rendido Paladín (...) El director de PAPELES DE SON ARMADANS, mientras desayuna, se imagina cronista de estos panoramas tiernos, viajero a lo que salte por estas trochas que casi no lo son, afortunado vagabundo coleccionista de paisajes amables, de horizontes amables (CELA, 1956, p. 4). 
Y no será esta revista, nacida a la sombra de un castillo, una "revista de combate", advierte, y sí "una tímida y quizás orgullosa revista de literatura y pensamiento, términos tan manidos como poco eficaces" (CELA, 1956, p. 5).

A seguir, explica el nombre de la revista:

'Son', partícula que puede preceder al nombre propio de los predios mallorquines, es un elemento privativo de la toponimia de la isla y que no existe en otras comarcas de lengua catalana. 'Son' es la contracción y la grafía moderna de 'Ço d'En'; 'ço', arcaico demostrativo neutro que viene del latin 'ecce hoc', y 'En', artículo personal catalán que procede del vocativo 'domine' y que se emplea, como título de cortesía, delante de los nombres propios de personas o de familia. La traducción castellana de 'ço' es 'esto' o 'lo'. 'En' equivale a 'don'o 'señor'. 'Son Berga', 'Son Bonet', 'Son Armadans' son nombres de propiedades - o que designan aún los lugares donde estas fincas rústicas estuvieron - o que significan, literalmente, 'lo del señor Berga', 'lo del señor Bonet', 'lo del señor Armadans'.

Pero no deja de hacerlo con humor:

[...] El director de PAPELES DE SON ARMADANS, al llegar a este punto y un poco harto ya de filologías pide, con su más persuasiva y templada voz, un vaso de vino de Binisalem, deleitoso, solemne y tinto como el apacible y untuoso sonar del fagot. (CELA, 1956, p. 9)

La revista que nace "por una abigarrada suerte de razones tan elementales que ya ni se entienden" (CELA, 1956, p.10) será una publicación liberal y tolerante, que pretendía hacer un puente entre aquellos que vivían en España y los que peregrinaban por las Américas $\mathrm{y}$, al mismo tiempo, tendrá una voluntad polifónica, preocupada con las culturas peninsulares. Los inicios de la revista fueron acompañados por conferencias, estando la primera a cargo de Blas de Otero. Con un auditorio compuesto de amigos, Cela pasaría a convertirse, de esa manera, en el referente cultural de Mallorca y conseguía decirle así adiós a la "negrura de la primera posguerra" (SOTELO, s/f, p. 200-204). El propio Sotelo trae el texto de Vidal Isern que era corresponsal de La vanguardia y que decía el 24 de febrero de 1959, alabando las actividades del escritor:

El señor Cela explicó seguidamente a los reunidos las gestiones personales llevadas a cabo para incorporarse a su querida Mallorca, a donde vino por unas semanas y lleva ya aquí, gustosísimo, varios años, las tareas culturales de una Semana de alturas espirituales en consonancia con el tema genérico Europa, habiendo conseguido la firme colaboración al efecto de figuras tan prestigiosas como el señor Menéndez Pidal, por el cual siente verdadero afecto y devoción ilimitada. Los demás conferenciantes serán el doctor López Ibor, de tanto prestigio clínico como intelectual; el joven polígrafo Julián Marías, el hondo escritor Laín Entralgo y el ilustre poeta y orador don José Maria Pemán.

Como resultado, observa Sotelo, Cela ahondó sus señas de identidad en los primeros números de la revista y la mantuvo hasta el año 1979:

Si por los riñones del genial novelista circulaba sangre de tres naciones, su andadura de hombre y de escritor se sintió vinculada a varias geografías. Una de ellas, -creo que la que define su dimensión de escritor universal- es la mallorquina. Cela -lo reconocía él mismo en el Auditorium de Palma el 20 de enero de 1977- escogió nacer de nuevo en Pollença y en Palma. Por ello, -y como también reconocía abiertamete el escritor padronés- "una considerable parte del mérito o de la culpa que se acumule en el parecer de las siguientes generaciones sobre el conjunto de mi obra, es tema del que deberán responder Mallorca y los mallorquines". Cela y Mallorca es un binomio esencial en la cultura española, polifónica y universal que tuvo en PSA -sol con rostro humano- el mejor, más honesto y leal escenario posible durante un cuarto del siglo XX (SOTELO, s/f, p. 200).

Papeles de Son Armadans se convirtió en una revista respetada y estimada entre los círculos intelectuales. En ella:

[...] se da cita amistosa lo más desenvuelto, ventilado y afanoso del vivir español. Y como en las viejas Revista de Occidente o Cruz y raya, salvando las distancias y las premuras de un tiempo de signo más ajetreado y diferente, se deja constancia de todo cuanto el oficio del pensamiento necesita cotidianamente. No dejar pasar nada en claro o en olvido. La mejor prueba son los prólogos -mejor: delantales- que a cada número pone su director. Allí nos encontramos con el ritmo espontáneo de su prosa, comentarios sobre todo lo que ha ido suponiendo algo -triunfal o calamitosopara el intelectual español (ZAMORA, s/f, s/p).

Ya habiéndose mudado para una casa del barrio El Terreno, estableció la redacción de la revista en el sótano de la propiedad. Casi en seguida (en 1957), fue elegido miembro de la Real Academia Española para ocupar el sillón Q. Las publicaciones continuaron durante mucho tiempo, y para Zamora (s/f) en ellas van a predominar:

[...] reflexiones, tan oportunas en nuestro momento, sobre el escritor, su soledad, su independencia, sus gozos y sus desventuras; no escasean juicios sobre la pedrea de los premios literarios, pedrea que va a acabar por mellar, si no herir de muerte, el paisaje de la 
literatura; se envuelve de emoción jugosa y de la mejor ley el recuerdo del entierro de Pío Baroja, una tarde de otoño, las gentes huidizas, el ataúd pobre y destiñendo, de igual modo le tiembla al prologuito ocasional hasta la puntuación, al evocar la muerte, en tierra extraña, de Antonio Machado: 'Poeta el más español de nuestros poetas, don Antonio, el Bueno, no pudo quedarse en la tierra que le vio nacer. A los españoles, que no supimos guardarlo, sólo nos resta llorar.' Se da siempre en esas páginas iniciales de cada mes de Papeles noticia o noticias, acorde vibración a lo sucedido con vocación de trascendencia: el premio Nobel a Juan Ramón Jiménez, a Camus, la muerte de Manuel Altolaguirre; se recuerda a Picasso, a Joan Miró, a un grupo de jóvenes pintores abstractos, a Gaudí, el discutido arquitecto; se comentan reuniones poéticas, se medita sobre la propia revista cada vez que un necesario balance se impone; se dedican fervorosos, humildes y evidentes homenajes a Menéndez Pidal, a Dámaso Alonso, a Vicente Aleixandre. Se recuerda a Gutiérrez Solana y se celebra la llegada a Mallorca de Américo Castro; se asoman curiosamente opiniones sobre ciudades, provincias del léxico, acaecer de los meses, la Academia, el apunte carpetovetónico, el Estado, los libros, la circunstancia actual de los españoles, los periódicos, la insatisfacción de los jóvenes, etc. Batiburrillo plural y aparentemente confuso, en el que el orden se va haciendo por su propio peso, desbrozándose, meditación abierta y consecuente, día a día manifiesta, hecha con dos adjetivos camino del olvido: meditación leal, meditación honesta. Y detrás de esos prologuitos, también día a día, una España que quiere vivir, dejar constancia de su hoy, también lealmente, honestamente (ZAMORA, s/f, s/p).

En 1964, el escritor estaba decidido a tener una propiedad en la isla y deseaba vivir permanentemente en Palma. De esta manera, con 48 años, se mudó para La Bonanova, calle Francisco Vidal Sureda, número 71, y pasó a concentrarse en su labor de escritor: Oficio de tinieblas 5, San Camilo 1936, Diccionario Secreto, Enciclopedia del erotismo son algunas de las obras que escribió.

La revista Papeles de Son Aramadans continuó siendo publicada y es importante destacar que, además de ofrecer sus páginas a escritores españoles en el exilio, Don Camilo también permitió que la publicación presentase textos en gallego, catalán y vasco, además de inglés. Publicó, también, números monográficos sobre Pablo Picasso, Joan Miró y Antoni Tapiès. Fueron 276 números publicados de1956 hasta 1979.

\section{El nombramiento como profesor - una nueva experiencia}

Por el R. D. 1288/1980 del 30 de junio, Camilo José Cela Trulock fue nombrado "Catedrático Extraordinario" en la Universidad de Palma, de la que ya era Doctor Honoris Causa, con toma de pose el 24 de julio de ese mismo año, y donde ejerció la docencia hasta que se jubiló, el 30 de setiembre de 1985. El que sería Premio Nobel de Literatura, el Marqués de Iria Flavia, Miembro correspondiente de la Academia Porteña del Lunfardo, Cartero honorario, Médico forense honorario, Bombero voluntario honorario, Alumno honoris causa, Presidente de honor de la Asociación de Amigos del Ferrocarril, Miembro del Colegio de Patafísica, impartiría lecciones de "Español coloquial" y "Dictadología tópica", esta última siendo "ciencia todavía por fundamentar y que debería conducir, en los sueños y deseos de Don Camilo, a la elaboración de un magno Diccionario Geográfico Popular de España" (CUADRADO, 2009, p. 228).

De la entrada del ilustre profesor Don Camilo, "el del premio", en "la Jerusalén académica", el profesor Cuadrado recuerda:

Por aquél entonces la delegación de Palma de Mallorca de la Facultad de Filosofía y Letras de la Universidad Central de Barcelona se había convertido en la Facultad de Filosofía y Letras de la recién creada Universidad de Palma de Mallorca (hoy Universitat de les Illes Balears), y el hoy Departamento de Filologia Espanyola, Moderna i Latina era conocido (poco y mal, para qué ocultarlo) como Departamento de Lengua y Literaturas Españolas, ocupando un sombrío rincón del beaterio de Son Malferit Extramuros cuyos 25 metros cuadrados habían ido dividiéndose por necesidades del servicio.

\section{Y con relación al acto en sí:}

[...] pese a su carácter estrictamente académico, fue seguido y aproximadamente divulgado por los medios de comunicación, llegando a merecer honores de reportaje gráfico en algunas revistas del corazón. (...) Apagados los focos de la fiesta iniciática, principió Don Camilo la lección nombrando a sus maestros-siempre el Don por delante, ejemplo de mesura y cortesía: Don Pedro Salinas, etc. - con aquella su voz de dar nombre a las cosas que todavía no son y emoción al recuerdo de las que fueron o pudieron o debieron ser, y empezó así lo que sería inolvidable rito semanal culminando invariablemente con una demótica ceremonia del café a la que el pícaro oficiante y convidador solía calificar de calculada captatio benevolentiae (CUADRADO, s/f, p. 228-229).

Los periodistas de la época destacaban que el maestro era el primero a llegar a la clase, a las 9:20 de la mañana. Apenas cuatro eran alumnos verdaderos, el resto eran asistentes, entre ellos el Decano de la Facultad y "fascinadas señoras endomingadas", hasta que Don Camilo "se decidió a echar mano de la sicalipsis y 
a salpimentar la teoría con ejemplos de muy dudosa ejemplaridad (...) que acabaron por despejar la sala dejándola en su más descarnada desnudez académica" (CUADRADO, 2009, p. 230).

\section{En las clases}

Los alumnos la pasaban muy bien, nos cuenta María Payeras Grau, su alumna del doctorado en la época, en artículo de periódico (PAYERAS, 1989). Don Camilo también les recibía en su casa de la Bonanova para impartir lecciones. Su nutrida biblioteca era puesta a disposición y el maestro discursaba "a su antojo", poniendo en circulación una botella de vino tinto "ritualmente compartido por todos los presentes, bebiendo a morro por riguroso turno de asiento y siguiendo el sentido de las agujas del reloj". Entre "trago y trago" conocieron sus colecciones ortodoxas y heterodoxas, que incluían "una estimable pinacoteca y una porción de singulares esquelas mortuorias".

Supieron que tenía un sello personal para sus cartas y que se lo habían entregado cuando le nombraron Cartero Honorario: "título merecido por una célebre encuesta que envió a todos los carteros de España solicitando información acerca de gentilicios, pseudogentilicios y otros vericuetos del dictado tópico, evitando, eso sí, contaminar con jerga académica unas preguntas para las que quería respuesta veraz y no muda admiración". Y supieron que el título lo recibió por obras que según Correos (2015), guardan estrecha relación con la labor de los carteros, como lo son el ensayo Elogio del correo, sus libros de viajes en los que aparecen los carteros y además, Viaje a la Alcarria, Del Miño al Bidasoa, Ávila y Judios Moros y Cristianos, que son "bellas lecciones de geografía postal".

En clases en que, con espíritu deportivo, se quejaba de que una vez más no le habían otorgado el Premio Cervantes, los alumnos disfrutaban de un excepcional recreo, mientras el escritor producía su Mazurca para dos muertos, - que posiblemente no sea lo que la crítica siempre pretendió, es decir, la historia de un asesinato y una venganza como eje argumental, y sí un viaje a sus raíces $^{1}$, obra con la cual obtendrá el Premio Nacional de Literatura.

Cierto día sorprendió a sus alumnos mostrando su laboratorio, que era:

Una reducida dependencia de escasos metros cuadrados, preservada de la luz solar y de los ruidos exteriores, ajena a la belleza del entorno, contenía un

\footnotetext{
1 Conforme Andres-Suarez, Irene. Mazurca para dos muertos de Camilo José Cela. Disponible en: <http://retro.seals.ch/cntmng?pid=v er-001:1988:13::129>. En: 09 enero 2015 .
}

escritorio de proporciones regulares y un catre adosado a la pared, sin que ningún agente susceptible de perturbar la paz o inducir a la distracción pudiera ser visible. En el suelo se amontonaban lo que el escritor denominó 'herramientas': algunos diccionarios y diversos libros de consulta con los que documentaba su trabajo. Sobre la mesa se apilaban unas cuartillas jeroglíficas, de apretada escritura, profusamente corregida, que algún admirable talento en criptografía camiliana debería después ordenar y pasar a limpio, ya que el escritor ha desdeñado sistemáticamente no ya la moderna tecnología informática, sino la más elemental y rudimentaria máquina de escribir, teniendo por superfluo o por lo menos ancillar todo intermediario entre su pulso personal y la página en blanco (PAYERAS, 1989).

Los estudiantes aprendieron sus lecciones. Quizá no de la manera ortodoxa, pero lecciones, al fin y al cabo. Y esta será la que más recordará María Payeras, la lección más importante:

Entre aquellas cuatro paredes, el ciego Gaudencio tocaba 'Ma petite Marianne' para los muertos Afouto y Moucho. Y mientras llovía mansa e interminablemente (...) se urdía una trama de avances y retrocesos donde un coro de personajes iba configurando otro retablo de humanidad que el narrador observaba con irónica, estremecedora y mal disimulada ternura (PAYERAS, 1899).

En una entrevista para Perfecto Cuadrado, Camilo José Cela recuerda sus años de profesor:

El contacto con los alumnos fue breve, unos pocos años, pero en cualquier caso muy aleccionador para mí... Sobre todo que empecé en un momento en que los alumnos estaban oficialmente sublevados, esto es, el poder contra el que había que luchar era el profesor, y fíjese, yo me acuerdo que, en el primer curso que dí, una chica, señora o señorita, no sé, vamos, su estado civil, pues esa chica fumaba porros en clase, jé, je, nada más que para irritar. Yo, bueno, es elemental, con no darte por enterado estarás al cabo de la calle, claro... Después, eso se fue calmando, y empezaron a estudiar un poco más, porque, claro, es que para las dos cosas no hay tiempo material... Sí, aquello fue una experiencia muy enriquecedora, muy saludable, ya lo creo... (CUADRADO, 2009, p. 231).

En sus palabras encontramos que en el inicio de la actividad había algo de incomodidad, y no podría ser diferente si, para incordiar, esa señora fumaba marihuana en su clase, pero vemos también que hubo una superación y posteriormente cierta satisfacción por parte del escritor y profesor. 


\section{Un maestro en lo suyo}

Hagamos una reflexión con lo que nos cuentan los que le conocieron en ese momento. Cuando Camilo José Cela llega a la Universidad para dar clases, ya era el prestigioso autor. No era un hombre que tuviese que hacer curriculum de ningún tipo, era miembro desde muy joven de la Real Academia Española, había fundado la revista Papeles de Son Armadans y la había sostenido durante años. También es importante recordar que no tenía estudios universitarios y estaba enfrentado con la realidad de la vida académica, aunque nadie se encontraba en un plano de igualdad con respecto a él, y posiblemente no podía cumplir la función de un catedrático con dedicación exclusiva creando escuela e impulsando la carrera académica de sus colegas de menor rango.

Evidentemente, su labor no era ni puede ser juzgada por los parámetros cotidianos habituales; Camilo José Cela era un maestro en lo que él sabía y en lo que era lo suyo. De esta manera, aquellos que comprendieron eso, como es el caso de los citados en estas líneas, se sabían privilegiados por gozar de una experiencia única, que otros en universidades, digamos, más consolidadas, no vivirían jamás. Sus clases pudieron haber hecho atisbar un horizonte para la investigación de aquellos que se interesaron por la Dictadología tópica, para cuya documentación poseía un archivo único e irrepetible ahora que tiende o ya ha desaparecido en España la cultura rural. Eso para quien se interesaba por la lingüística. Y aquellos orientados hacia la literatura tuvieron el privilegio de ver cómo un narrador admirable organizaba su vida y su trabajo, pues relatan que durante los meses en que escribió Mazurca para dos muertos, vivió como un anacoreta, durmiendo y escribiendo en un cuartucho minúsculo atestado de libros y papeles, aunque su casa tenía todo lo necesario para ser una finca de recreo, y Mallorca le ofrecía todo lo que la naturaleza tiene de más hermoso.

Su momento de recreo eran sus clases, sus alumnos. Y ellos estaban frente a alguien que poseía un anecdotario riquísimo, interminable e interesante. Había vivido hechos históricos fundamentales, se había relacionado con grandes personajes y otros ni tanto, conocía todo el mundo intelectual y político de la época, el Rey lo había designado Senador, había sido uno de los padres de la Constitución, pudiendo hablar de todo y de todos con naturalidad. Y también era el fabulador que les hablaba a sus alumnos como si estos estuviesen en la tertulia del Café Gijón, de la que fue asiduo. Mucho más de lo que se puede pedir: oír a quien era capaz de crear un notable efecto estético, con un castellano muy rico y de enorme versatilidad y siempre tendiendo a la comicidad.

Disfrutar de esa magnífica oralidad, herencia de su generación, adquirida en las sobremesas y veladas caseras es, sin duda, formidable. Y a esto se le suma la grata experiencia de encontrar la generosidad de un hombre que puso a disposición su extraordinaria biblioteca personal en una época en que el acceso a los materiales era estricto. Y también, ver que se comportaba siguiendo el protocolo correspondiente, presidiendo tribunales de tesis y tesinas con su voz retumbante que imponía respeto, pero siempre haciéndolo de forma correcta entre aquellos que aceptaban su presencia con naturalidad.

Don Camilo enseñaba deleitando y, antes de recibir el Premio Nobel y ser transformado, ya era el multipremiado por excelencia, que sabía dar valor a lo que realmente era importante. Decía claramente: "esto de los premios es un doméstico juego para mansuetos, novelistas bajo palabra de honor y escritores sobre las aguas de la mar". Y resumía así su sentimiento: "queda un poco ridículo el decirlo, bien lo sé, pero les declaro casi solemnemente que mi mejor premio son ustedes, mis amigos, que son numerosos y generosos" (CUADRADO, 2009, p. 234).

Tal vez se pueda decir, en la distancia y por los relatos de los que lo conocieron, que con el tiempo Don Camilo se divertía enseñando, que los alumnos se deleitaban aprendiendo, pero sobre todo, que prevalecía entre ellos algo mucho mayor, un sentimiento de respeto y amistad. Posiblemente no le dio a la Universidad un gran impulso institucional. Tal vez ni siquiera dejó seguidores, pero para unos pocos privilegiados, su presencia fue un hecho excepcional que verdaderamente les enriqueció la vida.

\section{Referencias}

ANDRES-SUAREZ, Irene. Mazurca para dos muertos de Camilo José Cela. Disponible en: http://retro.seals.ch/ cntmng?pid=ver-001:1988:13::129 En 09/01/2016.

AZNAR, Manuel S. Escritores, editoriales y revistas del exilio republicano de 1939. Diponible en: <https://books.google.com. $\mathrm{br} /$ books?id=NPnDxMEjx $5 \mathrm{kC} \& p g=\mathrm{PA} 286 \& \mathrm{lpg}=\mathrm{PA} 286 \& \mathrm{dq}=\mathrm{c}$ amilo + josé + cela $+y+$ las + revistas \&source $=$ bl\&ots $=o B \_7 J 259 v P$ \&sig=-7lnQH7ERN0Dj-_Ej9u_9ZdY390\&hl=pt-BR\&sa=X\& ved=0ahUKEwjvjLrmzafKAhUMiZAKHQQBC6EQ6AEILj $\mathrm{AC} \# \mathrm{v}=$ onepage $\& \mathrm{q}=$ camilo $\% 20$ josé $\% 20$ cela $\% 20 \mathrm{y} \% 201 \mathrm{las} \% 20$ revistas \&f=false $>$. En: 13 enero 2015.

CELA, Camilo José. Obras completas. Barcelona: Planeta-De Agostini, 1989.

CORREOS. Disponible en: < http://www.correos.es/ss/Satellite/ site/museo-1349168932144-museo_salas/detalle_museosidioma $=$ es_ES $>$. En: 13 enero 2016.

CUADRADO, Perfecto. El profesor Camilo José Cela. En: PAYERAS, Grau María; RIERA, Carme. 1959, de Collioure a Formentor. Madrid: Visor, 2009.

DÍAZ ANGEL, A. Foto Matón humano y literario de Camilo José Cela y su obra. Disponible en: <http://toulouse.cervantes. es/imagenes/file/biblioteca/autores/cela.pdf $>$. En: 13 enero 2015. 
DICCIONARIO de la Real Academia Española. Disponible en: $<$ http://www.rae.es>. En: 13 enero 2016.

FUNDACIÓN Camilo José Cela. <http://www.celafund.es>.

PAYERAS, Grau María. “Ustedes lo pasen bien”. En: Última hora, 22 de octubre de 1989. p. V.

REVISTA Papeles de Son Armadans. Presentación de la versión digital. Disponible en: <http://www.papelesdesonarmadans. com/Revista.htm>. En: 13 enero 2016.

REVISTA Papeles de Son Armadans. Disponible en: <http:// www.papelesdesonarmadans.com/PDF/PSA_muestra_25pdf $>$. En: 13 enero 2016.

SOTElo, Vázquez, A. Camilo José Cela: Perfiles de un escritor. Disponible en: <https://books.google.com.br/books? $\mathrm{id}=$ WZIPAwAAQBAJ\&pg=PA196\&lpg=PA196\&dq=la + vida + $\mathrm{de}+$ cela + en + mallorca $\&$ source $=$ bl\&ots $=$ adrVgwLQLe $\&$ sig=UVh3_23FOK2VMrFbGQgk31hMrmc\&hl=pt-BR\& $\mathrm{sa}=$ X\& ved $=0$ ahUKEwiDk-XziKbKAhWHIZAKHftXAM0Q6 AEIPjAE $\# \mathrm{v}=$ onepage $\& \mathrm{q}=\mathrm{la} \% 20 \mathrm{vida} \% 20 \mathrm{de} \% 20$ cela $\% 20 \mathrm{en} \%$ 20mallorca\&f=false $>$. En: 13 enero 2016.

ZAMORA, Alonso V. Camilo José Cela: (acercamiento a un escritor). Disponible en: <http://www.cervantesvirtual.com/ obra-visor/camilo-jos-cela--acercamiento-a-un-escritor-0/ html/ff6e654e-82b1-11df-acc7-002185ce6064_9.html>. En: 13 enero 2015.

Recebido: 03/11/2015

Aprovado: 22/01/2016

Contato: rdcastiglioni@gmail.com 